Disclosure of Interests: Jérémy Boulestreau: None declared, Marie Maumus Employee of: Bauerfeind France, Pauline Rozier: None declared, Christian Jorgensen Shareholder of: Medxcell sciences, Consultant of: Medxcell sciences, Daniele Noel Shareholder of: Medxcell sciences, Consultant of: Medxcell sciences DOI: 10.1136/annrheumdis-2021-eular.2401

\section{POS0375 \\ CHAPERONE-MEDIATED AUTOPHAGY IS A HALLMARK OF JOINT DISEASE IN OSTEOARTHRITIC PATIENTS}

1. Lorenzo ${ }^{1}$, U. Nogueira-Recalde ${ }^{1}$, N. Oreiro ${ }^{2}$, J. A. Pinto Tasende ${ }^{2}$, M. Lotz ${ }^{3}$, F. J. Blanco ${ }^{1,2}$, B. Carames ${ }^{1} .{ }^{1}$ Instituto de Investigación Biomédica de A Coruña (INIBIC), Unidad de Biología del Cartilago, Grupo de Investigación en Reumatología, A Coruña, Spain; ${ }^{2}$ Complejo Hospitalario Universitario A Coruña, Grupo de Reumatología Clínica, A Coruña, Spain; ${ }^{3}$ Scripps Research, Department of Molecular Medicine, La Jolla, United States of America

Background: In Osteoarthritis (OA), defects in macroautophagy (autophagy) are evident and precede joint damage. Indeed, pharmacological activation of autophagy protects against joint damage.

Objectives: Therefore, identifying hallmarks associated with specific autophagy subtypes could shed light to fundamental mechanisms of joint disease.

Methods: A comparative analysis of 35 autophagy genes was performed from blood from the Prospective OA Cohort of A Coruña (PROCOAC). Non-OA subjects (Age:61,44 $\pm 1,16$ years; BMI:25,25 $\pm 0,52$; Females, $n=18$ ) and Knee OA subjects (Age:65,50 $\pm 1,05$ years; BMI:29,55 $\pm 0,67$; Females, $n=18$, OA grade III-IV) were profiled using an autophagy gene expression array by SYBR green qPCR. Confirmatory studies were performed in blood from Non-OA subjects (Age:60,13 $\pm 1,12$ years; BMI:24,85 $\pm 0,59$; Females; $n=30$ ) and Knee-OA subjects (Age:68,4 $\pm 1,11$ years; BMI:29,65 $\pm 0,55$; Females; $n=30$, OA grade III-IV) by Taqman qPCR. The candidate gene was evaluated in human knee joint tissues (cartilage, meniscus, ligaments, synovium) with different $\mathrm{KL}$ grades (Age: $\mathrm{KLO}=28,3 \pm 4,50 ; \mathrm{KL} 2=77 \pm 6,08 ; \mathrm{KL} 4=62,3 \pm 3,05, \mathrm{n}=3$ ) and in both spontaneous aging $(2,6,12,18$, and 30 months old, $n=3)$ and surgically-induced OA (10 weeks after surgery, $n=4$ ) in mice by $\mathrm{IHC}$. The functional consequences were studied in T/C28a2 and primary human OA chondrocytes. Autophagy, FOXO, Chaperone-mediated autophagy (CMA), inflammation, and cellular senescence were analyzing by gene and protein expression. Moreover, oxidative stress and cell death were evaluated by FACS. The contribution of CMA to chondrocyte homeostasis was evaluated by studying the capacity of CMA to restore proteostasis upon autophagy deficiency by siATG5.

Results: 15 autophagy-related genes were significantly downregulated in blood from knee OA patients compared to non-OA patients. No significant upregulation was found for any studied gene, although a trend towards upregulation was found in genes involved in the mTOR pathway. Four key autophagy-related genes, including ATG16L2, ATG12, ATG4B and MAP1LC3B were found downregulated in knee OA patients. Interestingly, HSP90AA1 and HSPA8, CMA markers involved in stress response and protein folding, were downregulated. Confirmatory studies showed a significant downregulation of MAP1LC3B and HSP90AA1 in blood from knee OA patients. Remarkably, HSP90A was found reduced in femoral cartilage (medial and lateral), meniscus and ACL. Moreover, this reduction was higher in medial cartilage compared to lateral cartilage and meniscus, while in synovial membrane, HSP90A expression was found increased. This expression signature was dependent on OA grade severity. In addition, we observed a decrease of HSP90A with aging and OA in mice. The functional consequences of HSP90AA1 gene silencing are related to an increase in NFKB, MMP13, and p16 expression. Interestingly, LAMP2A, a key CMA mediator, HSPA8, MAP1LC3B and FoxO1 expression were upregulated in chondrocytes with HSP90AA1 deficiency, which might indicate an early response to maintain homeostasis. On the other hand, LAMP2A protein is decreased upon HSP90AA1 deficiency, while LC3II and p62 were increased, indicating a failure in the autophagy flux that leads to impaired lysosomal degradation.

Moreover, p21, p16 and prbS6 were increased upon HSP90AA1 deficiency, besides increasing mitochondrial ROS production and apoptosis. ATG5 silencing blocks autophagy by reducing LC3II and increasing prbs6, p62, p16 and p21. Interestingly, LAMP2A and HSP90A were found increased, indicating a possible compensative activation of CMA in response to autophagy defects. These results support that HSP90A has an important role in chondrocyte homeostasis by participating in the cross-talk between CMA and autophagy.

Conclusion: Taking together, we identified HSP90A, a CMA regulator, as critical in chondrocyte homeostasis. These disease mechanisms are relevant in OA and constitute hallmarks potentially useful to prevent OA progression. REFERENCES:

[1] Caramés B, et al. Arthritis Rheum. 2010, 2015;

[2] Caramés B, et al. Ann Rheum Dis. 2012.

Disclosure of Interests: None declared

DOI: 10.1136/annrheumdis-2021-eular.2639

\section{\begin{tabular}{|l|l}
\hline POS0376 MONOMERIC C REACTIVE PROTEIN (MCRP) \\
\hline
\end{tabular} REGULATES INFLAMMATORY RESPONSES IN HUMAN AND MOUSE CHONDROCYTES}

C. Ruiz-Fernández ${ }^{1}$, M. González-Rodríguez ${ }^{1}$, V. Francisco¹, I. M. Rajab ${ }^{2}$ R. Gómez Bahamonde ${ }^{3}$, J. Conde Aranda ${ }^{1}$, F. Lago ${ }^{4}$, J. Pino ${ }^{1}$, A. Mobasheri ${ }^{5}$, M. A. González-Gay ${ }^{6}$, A. Mera Varela ${ }^{7}$, L. A. Potempa ${ }^{2}$, O. Gualillo ${ }^{1} .{ }^{1}$ Health Research Institute of Santiago de Compostela (IDIS), NeuroEndocrine Interactions in Rheumatic and Inflammatory Diseases Group, Santiago de Compostela, Spain; ${ }^{2}$ Roosevelt University, College of Pharmacy, Schaumburg, United States of America; ${ }^{3}$ Health Research Institute of Santiago de Compostela (IDIS), Musculoskeletal Pathology Laboratory, Santiago de Compostela, Spain; ${ }^{4}$ Health Research Institute of Santiago de Compostela (IDIS), Molecular and Cellular Cardiology Group, Santiago de Compostela, Spain; ${ }^{5}$ University of Oulu, Research Unit of Medical Imaging, Physics, and Technology, Faculty of Medicine, Oulu, Finland; ${ }^{6}$ Hospital Universitario Marqués de Valdecilla, IDIVAL, University of Cantabria, Epidemiology, Genetics and Atherosclerosis Research Group on Systemic Inflammatory Diseases, Santander, Spain; ${ }^{7}$ Santiago University Clinical Hospital, Division of Rheumatology, Santiago de Compostela, Spain

Background: C-reactive protein (CRP) is an acute-phase protein that is used as an established biomarker to follow disease severity and progression in a plethora of inflammatory diseases. However, its pathophysiologic mechanisms of action are still poorly defined and remain elusive. CRP, in its pentameric form, exhibits weak anti-inflammatory activity. On the contrary, the monomeric isoform (mCRP) exhibits potent pro-inflammatory properties in endothelial cells, leukocytes, and platelets. So far, no data exists regarding mCRP effects in human or mouse chondrocytes Objectives: This work aimed to verify the pathophysiological relevance of mCRP in the etiology and/or progression of osteoarthritis (OA)

Methods: We investigated the effects of $\mathrm{mCRP}$ in cultured human primary chondrocytes and in the chondrogenic ATDC5 mouse cell line. We determined mRNA and protein levels of relevant factors involved in inflammatory responses and the modulation of nitric oxide synthase type II (NOS2), an early inflammatory molecular target. Results: We demonstrate, for the first time, that monomeric $C$ reactive protein increases NOS2, COX2, MMP13, VCAM1, IL-6, IL-8, and LCN2 expression in human and murine chondrocytes. We also demonstrated that NF-kB is a key factor in the intracellular signaling of $\mathrm{mCRP}$-driven induction of pro-inflammatory and catabolic mediators in chondrocytes.

Conclusion: mCRP exerts a sustained catabolic effect on human and murine chondrocytes, increasing the expression of inflammatory mediators and proteolytic enzymes, which can promote extracellular matrix (ECM) breakdown in healthy and OA cartilage. In addition, our results implicate the NF-kB signaling pathway in catabolic effects mediated by mCRP.

\section{REFERENCES:}

[1] Sproston NR, Ashworth JJ. Role of C-reactive protein at sites of inflammation and infection. Front Immunol. 2018;9(APR). doi:10.3389/fimmu.2018.00754

[2] Francisco V, Pérez T, Pino J, et al. Biomechanics, obesity, and osteoarthritis. The role of adipokines: When the levee breaks. J Orthop Res 2018;36(2):594-604. doi:10.1002/jor.23788

[3] Kozijn AE, Tartjiono MT, Ravipati S, et al. Human C-reactive protein aggravates osteoarthritis development in mice on a high-fat diet. Osteoarthr Cartil. 2019;27(1):118-128. doi:10.1016/j.joca.2018.09.007

[4] Rajab IM, Majerczyk D, Olson ME, et al. C-reactive protein in gallbladder diseases: diagnostic and therapeutic insights. Biophys Reports. 2020;6(23):49-67. doi:10.1007/s41048-020-00108-9

[5] WuY, Potempa LA, El Kebir D, Filep JG. C-reactive protein and inflammation: conformational changes affect function. Biol Chem. 2015;396(11):1181-1197. doi:10.1515/hsz-2015-0149

[6] Thiele JR, Zeller J, Bannasch H, Stark GB, Peter K, Eisenhardt SU. Targeting C-Reactive Protein in Inflammatory Disease by Preventing Conformational Changes. Mediators Inflamm. 2015;2015(372432):9. doi:10.1155/2015/372432

[7] Khreiss T, József L, Hossain S, Chan JSD, Potempa LA, Filep JG. Loss of pentameric symmetry of C-reactive protein is associated with delayed apoptosis of human neutrophils. J Biol Chem. 2002;277(43):40775-40781. doi:10.1074/jbc.M205378200

[8] Jia ZK, Li HY, Liang YL, Potempa LA, Ji SR, Wu Y. Monomeric C-reactive protein binds and neutralizes receptor activator of NF- $\mathrm{kB}$ ligand-induced osteoclast differentiation. Front Immunol. 2018;9(FEB). doi:10.3389/fimmu.2018.00234

[9] Francisco V, Ruiz-Fernández C, Pino J, et al. Adipokines: Linking metabolic syndrome, the immune system, and arthritic diseases. Biochem Pharmacol. 2019;165:196-206. doi:10.1016/j.bcp.2019.03.030

[10] Ullah N, Ma FR, Han J, et al. Monomeric C-reactive protein regulates fibronectin mediated monocyte adhesion. Mol Immunol. 2020;117:122-130. doi:10.1016/j.molimm.2019.10.013

[11] Boras E, Slevin M, Alexander MY, et al. Monomeric C-reactive protein and Notch-3 co-operatively increase angiogenesis through PI3K signalling pathway. Cytokine. 2014;69(2):165-179. doi:10.1016/j.cyto.2014.05.027

Disclosure of Interests: None declared

DOI: 10.1136/annrheumdis-2021-eular.4290 